\title{
A Dual-band Outphasing Transmitter using Broadband Class E Power Amplifiers
}

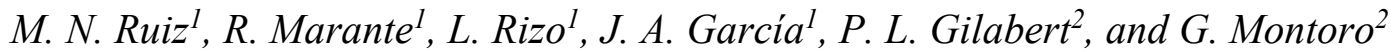 \\ ${ }^{I}$ Dept. Communications Eng., Univ. Cantabria, Santander, 39005, Spain \\ ${ }^{2}$ Dept. Signal Theory and Communications, Univ. Politècnica Catalunya, Castelldefels, 08860, Spain
}

\begin{abstract}
In this paper, a dual-band outphasing transmitter (able of operating either at $770 \mathrm{MHz}$ or $960 \mathrm{MHz}$ frequency bands) is presented. Two broadband RF power amplifiers (PAs) have been designed over packaged GaN HEMT devices, switching close to the nominal zero-voltage and zerovoltage-derivative class $\mathbf{E}$ conditions. A reactive combiner, using transmission lines of appropriate electrical lengths at both bands, together with compensating reactances, allows positioning the drain impedance loci to produce high efficiency and good dynamic range profiles. Average drain efficiency figures over $68 \%$ and $38 \%$ have been measured for WCDMA signals with a peak-to-average power ratio (PAPR) of $5.1 \mathrm{~dB}$ and $8.4 \mathrm{~dB}$, respectively.
\end{abstract}

Index Terms - Chireix, class E, efficiency, GaN HEMT, power amplifier, outphasing transmitter.

\section{INTRODUCTION}

In recent years, several efforts have been dedicated to design wireless communication systems with multi-band and multi-standard capabilities. Processing signals in multiple bands with a single transmitting architecture allows reducing the number of components and consequently the cost of the RF front-end. If doing it in a highly efficient way, implementing dynamic bias or load modulation techniques, the associated power savings may help cutting the operational expenses or lead to the extension of the battery lifetime.

In the particular case of the outphasing or Chireix transmitting scheme [1], the signal envelope is coded in the outphasing angle between two constant-amplitude components, that once amplified, are added for recovering the desired amplitude and phase variations. The reactive combiner forces a mutual load modulation of the constituting PAs in order to improve the efficiency versus output power profile. With an asymmetric version of such combiner [2], the drain impedance loci were set close to the zero voltage switching (ZVS) path, which would lead to a theoretical $100 \%$ efficiency, proving the benefits of introducing class-E amplifiers in this topology. Impressive and competitive results have been recently reported in [3], following this principle.

In this paper, a dual-band implementation of this outphasing transmitting architecture is presented. A combiner, using transmission lines and compensating reactances, is adjusted to force near optimum load modulation conditions at the selected frequency bands, over two broadband GaN HEMT class E power amplifiers.

\section{BROADBAND CLASS E AMPLIFIER}

In the original class E topology of [4], the quality factor of the series resonant LC circuit should be high enough as to guarantee that the current delivered to the load at the design frequency, $f_{o}$, is a sinusoid. As a drawback, the drain impedance at the fundamental gets apart from the nominal or optimum value, $Z_{d}\left(\omega_{o}\right)=0.1836 /\left(\omega_{o} . C_{\text {out }}\right)+j * 0.2116 /\left(\omega_{o} . C_{\text {out }}\right)$, with $C_{\text {out }}$ the equivalent output capacitance of the device in OFF-state, when varying the operating frequency [5]. This leads to a narrowband characteristic in terms of efficiency, besides an output power profile decreasing with frequency, which limits the use of these topologies for broadband PAs.

Several solutions have been proposed in the literature to improve the bandwidth of class $\mathrm{E}$ amplifiers, either resonating $C_{\text {out }}$ [6] or introducing novel continuous-mode concepts [7], among others. In the proposed design (see Fig. 1), conceived to cover from $770 \mathrm{MHz}$ to $960 \mathrm{MHz}$, a parallel $L_{l p} C_{l p}$ circuit was tuned between the bands of the second and third harmonics. Its quality factor, $Q_{l p}$, was selected as a trade-off between the desired termination at the harmonics by one side (a low $Q_{l p}$ would be preferred to keep a condition as close as possible to the open) and the desired termination at the fundamental by the other (a high $Q_{l p}$ would lead to a lower equivalent inductance at the operating frequency band, consequently reducing the sensitivity of such impedance to frequency variation). This inductance and the capacitance to ground, $C_{2 p}$, allowed transforming from $50 \Omega$ to a fundamental impedance locus near the nominal values. The input matching network, $C_{i n}$ and $L_{i n}$, was adjusted to minimize the gain ripple.

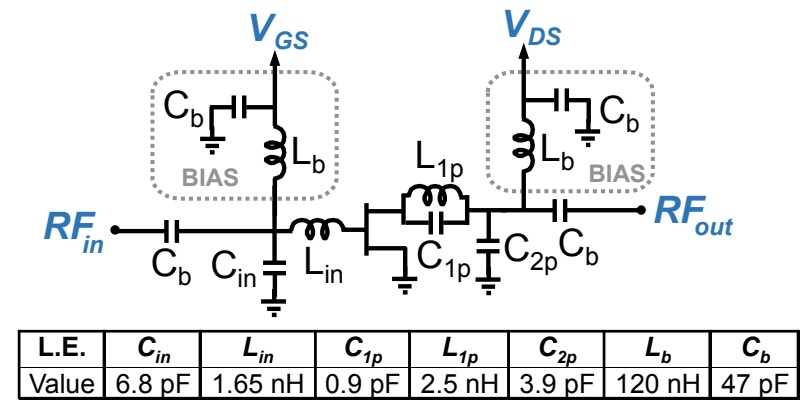

Fig. 1. Simplified schematic of the proposed broadband high efficiency PAs, approximating class E operation. 
Two amplifiers were implemented, over the CGH35030F GaN HEMT device from Cree Inc. Air Core coils from Coilcraft and multilayer ceramic capacitors from ATC have been employed. The transistor was operated at $V_{G S}=-3.8 \mathrm{~V}$ and $V_{D S}=28 \mathrm{~V}$. In Fig. 2, the output power and efficiency profiles with frequency, measured for one of them, are plotted. Drain efficiency values of $83.8 \%$ and $82.5 \%$ have been estimated at $770 \mathrm{MHz}$ and $960 \mathrm{MHz}$, respectively.

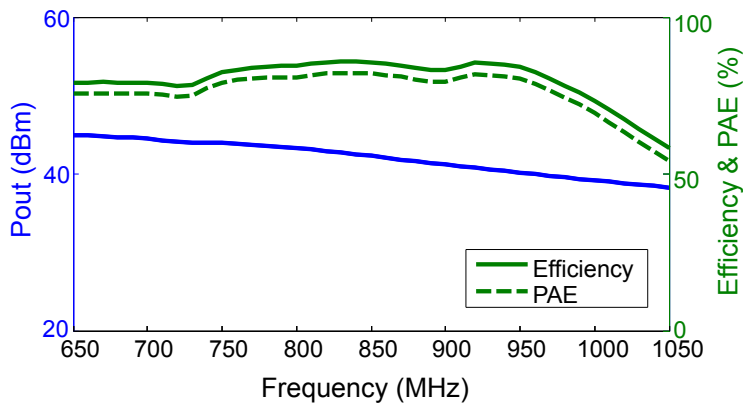

Fig. 2. Measured output power, efficiency and power added efficiency (PAE) characteristics with frequency.

\section{OUTPHASING TRANSMITTER}

The simplified schematic of the proposed dual-band outphasing transmitter, using the previously described broadband PAs, is presented in Fig. 3. It mainly follows the topology by Beltran and co-authors in [3]. Although a broadband combiner could have been designed instead, not a trivial task, it was decided to take full advantage of the rotation of the drain impedance loci over the Smith Chart with frequency, due to the variation of the electrical lengths of the constituting transmission lines.

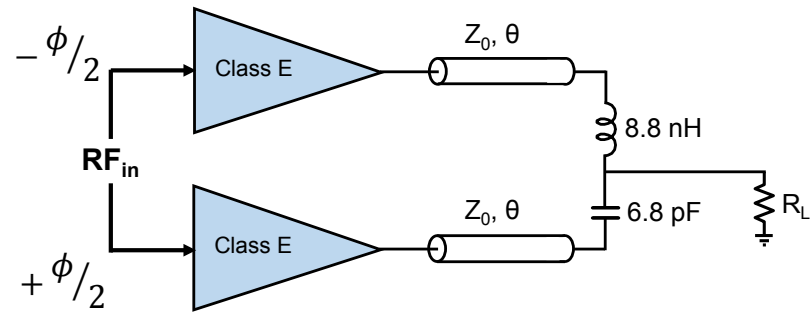

Fig. 3. Dual-band outphasing transmitting topology.

The length of these lines together with the value for the compensating or Chireix reactances was adjusted to produce near optimal load modulation paths at both frequency bands. As in [8], a simple switch model of the transistor was extracted, characterizing the ON-state resistance, $R_{\text {on }}$, and $C_{\text {out }}$. With the aid of multi-harmonic tuners, for terminating the second and third harmonics in the theoretical open conditions, the load-pull contours were obtained through simulations in the AWR platform. Considering the variation of the load-pull results with frequency, and for sake of clarity, only the contours at a middle frequency, $865 \mathrm{MHz}$, have been presented in Fig. 4. As it may be appreciated, the drain impedance loci due to the combiner may be set as to cut as many output power circles as possible, while staying in the zone of high drain efficiency. Attention should be also put to the fact that the output power increases with the outphasing angle at $770 \mathrm{MHz}$, while decreases at $960 \mathrm{MHz}$.

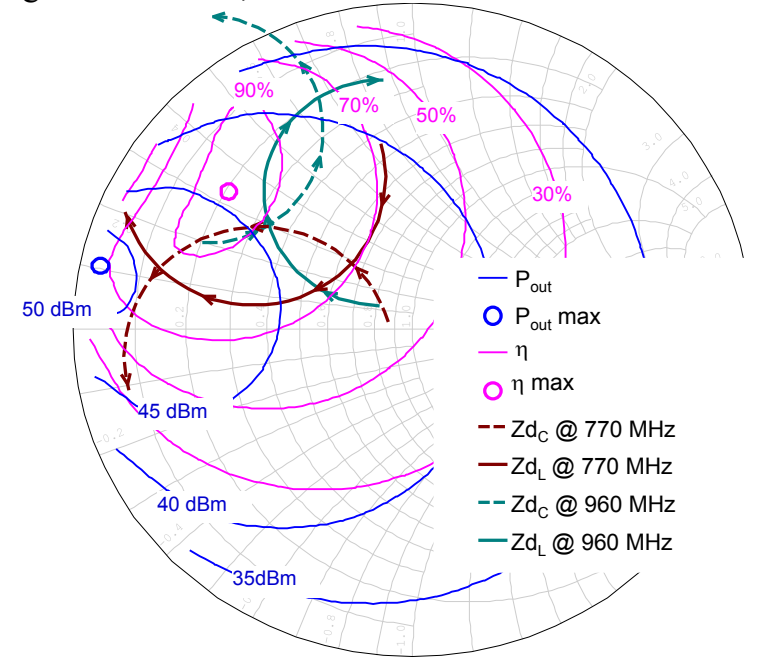

Fig. 4. Load-pull $P_{\text {out }}$ and $\eta$ circles. The impedance loci at the drain terminals are also depicted (the $\mathrm{L}$ and $\mathrm{C}$ subscripts indicate the branch with the inductance and capacitance, respectively).

In Fig. 5, a photograph with details of the implementation is shown. A set of SMA connectors was employed, in addition to the microstrip lines at the output of the PAs and the combiner inputs, to approximately fit the required transmission line length.

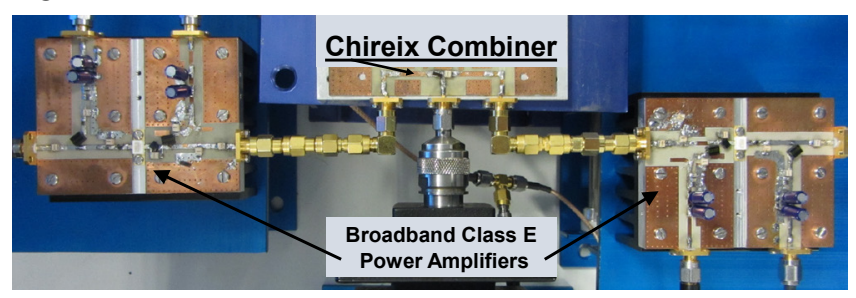

Fig. 5. Photograph with details of the amplifiers and the reactive or Chireix combiner.

\section{MEASUREMENT RESULTS}

\section{A. Static Profiles}

The output power and efficiency profiles were first characterized in terms of the outphasing angle. The phase shift between the $\mathrm{CW}$ excitation signals was adjusted, step by step, with the aid of the employed vector signal generators (VSGs) from Agilent Technologies. The obtained results at $770 \mathrm{MHz}$ and $960 \mathrm{MHz}$ are plotted in Fig. 6. The outphasing angle axis represents the phase difference at the inputs of the RF PAs (the impact of unbalances in the driving circuits has been removed). As expected from simulations, the output power increases with the angle at one band, while decreases at the other. The drain efficiency keeps over $60 \%$ for a power backoff of $8.5 \mathrm{~dB}$ and $8.1 \mathrm{~dB}$, at $770 \mathrm{MHz}$ and $960 \mathrm{MHz}$, respectively. 
TABLE I

POUT, EFFICIENCY, PAE AND ACPR RESULTS WITH WCDMA SIGNALS

\begin{tabular}{|c|c|c|c|c|c|c|c|c|c|c|}
\hline \multirow[b]{3}{*}{ Signal } & \multirow{2}{*}{\multicolumn{2}{|c|}{ Pout (W) }} & \multirow{2}{*}{\multicolumn{2}{|c|}{$\eta(\%)$}} & \multirow{2}{*}{\multicolumn{2}{|c|}{ PAE (\%) }} & \multicolumn{4}{|c|}{ ACPR (dB) } \\
\hline & & & & & & & \multicolumn{2}{|c|}{ Adj. $5 \mathrm{MHz}$} & \multicolumn{2}{|c|}{ Alt. $10 \mathrm{MHz}$} \\
\hline & $770 \mathrm{MHz}$ & $960 \mathrm{MHz}$ & $770 \mathrm{MHz}$ & $960 \mathrm{MHz}$ & $770 \mathrm{MHz}$ & $960 \mathrm{MHz}$ & $770 \mathrm{MHz}$ & $960 \mathrm{MHz}$ & $770 \mathrm{MHz}$ & $960 \mathrm{MHz}$ \\
\hline WCDMA & 12.64 & 10.76 & 70.48 & 68.62 & 61.78 & 63.72 & Low -56.5 & $\begin{array}{ll}\text { Low }-55 \\
\end{array}$ & Low -60 & Low -61 \\
\hline WCDMA & & & & & & & Low -55 & Low -52 & Low -59 & Low -55 \\
\hline $8.4 \mathrm{~dB}$ & 6.04 & 5.021 & 38.52 & 39.92 & 28.58 & 33.83 & Up -58 & Up -55 & Up -60 & Up -58 \\
\hline
\end{tabular}

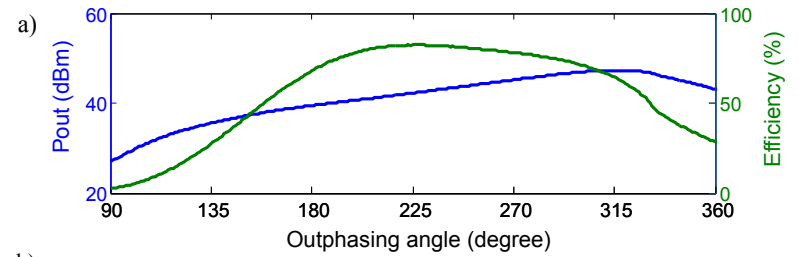

b)

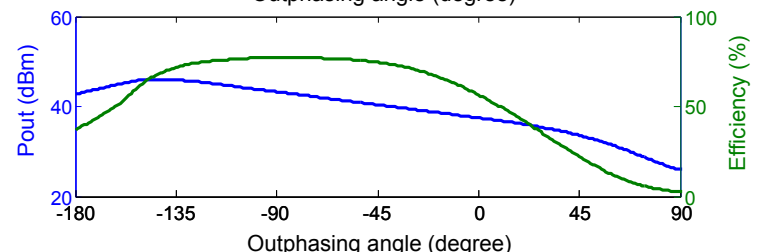

Fig. 6. Measured evolution of output power and efficiency profiles with the outphasing angle at a) $770 \mathrm{MHz}$ and b) $960 \mathrm{MHz}$.

\section{B. Dynamic Performance}

In order to extract the outphasing-to-AM and outphasing-toPM dynamic profiles, a triangle-shaped outphasing signal with a repetition frequency of $100 \mathrm{kHz}$ was sent from Matlab to the VSGs. The evolution of the amplitude and phase components of the output signal envelope was captured with the aid of the 89600 Vector Signal Analyzer. No significant memory effects were observed. Using a current probe, the evolution of the drain biasing current waveform was also measured.

Look-up tables (LUTs) were then adjusted for implementing a very simple memoryless DPD technique. Although longterm memory effects may appear at higher envelope frequencies, the only purpose of these experiments was roughly estimating the capability of the transmitter when reproducing complex modulated signals in a nearly linear way. In order to verify the impact of the envelope statistics on the average efficiency, attending to the above presented profiles, two WCDMA signals $(5 \mathrm{MHz})$ with PAPR values of $5.1 \mathrm{~dB}$ and $8.4 \mathrm{~dB}$, respectively, were selected.

In Table I, a comparison of the measured figures-of-merit is presented. Average output power, drain efficiency and PAE are included, together with the adjacent channel and alternate channel power ratios (ACPR). The adjacent and alternate channel power levels were integrated over a $30 \mathrm{kHz}$ bandwidth at $5 \mathrm{MHz}$ and $10 \mathrm{MHz}$ spacing with respect to the desired channel central frequency $(770 \mathrm{MHz}$ or $960 \mathrm{MHz})$.

The drain efficiency figures are over $68 \%$ for the signal with a moderate $5.1 \mathrm{~dB}$ PAPR value, while nearly $40 \%$ when reproducing the one with a PAPR of $8.4 \mathrm{~dB}$. Simulations in Matlab, using the measured amplitude and $I_{d d}(t)$ profiles, together with the probability density functions of the signal envelopes, fit quite well to the measured figures. Since nulls or very low values of the envelope may not be reproduced with a pure outphasing mode (see Fig. $6 P_{\text {out }}$ profiles), the achievable linearity would be limited. In fact, according to the ACPR values in Table I, only the adjacent channel distortion would satisfy the standard specifications.

\section{CONCLUSION}

A dual-band outphasing transmitter, combining two broadband class $\mathrm{E}$ power amplifiers and a reactive combiner, has been presented. The drain impedance loci may be conveniently positioned at both operating bands, resulting in high efficiency and good dynamic range profiles versus the outphasing angle. Average drain efficiency figures over $68 \%$ and nearly $40 \%$ have been measured for WCDMA signals with a peak-to-average power ratio of $5.1 \mathrm{~dB}$ and $8.4 \mathrm{~dB}$. Future actions include the use of a hybrid mode, allowing envelope variations in the RF excitation signals, together with an enhanced DPD for reducing the remaining distortion.

\section{ACKNOWLEDGEMENT}

This work was supported by MINECO through projects TEC2011-29126-C03 (-01, co-funded with FEDER, and -02), and Consolider CSD2008-00068. The kind assitance provided by Mr. Ryan Baker, Cree Inc., is also appreciated.

\section{REFERENCES}

[1] H. Chireix, "High Power Outphasing Modulation," Proc. IRE, vol. 23, pp. 1370-1392, Nov. 1935.

[2] R. Beltran, F. H. Raab and A. Velazquez, "HF Outphasing Transmitter using Class-E Power Amplifiers," IEEE MTT-S Int. Microw. Symp., pp. 757-760, June 2009.

[3] D. A. Calvillo-Cortes, M. P. van der Heijden, M. Acar, M. de Langen, R. Wesson, F. van Rijs, and L. C. N. de Vreede, "A Package-Integrated Chireix Outphasing RF Switch-Mode HighPower Amplifier," IEEE Trans. Microw. Theory Tech., vol. 61, pp. 3721-3732, Oct. 2013.

[4] N. O. Sokal and A. D. Sokal, "Class E, A New Class of HighEfficiency Tuned Single-Ended Switching Power Amplifiers," IEEE J. Solid-State Circ., vol. SC-10, pp. 168-176, June 1975.

[5] F. H. Raab, "Idealized operation of the class E tuned power amplifier," IEEE Trans. Circuits Syst., vol. 24, pp. 725- 735, Dec. 1977.

[6] N. Kumar, C. Prakash, A. Grebennikov, and A. Mediano, "High-Efficiency Broadband Parallel-Circuit Class E RF Power Amplifier with Reactance-Compensation Technique," IEEE Trans. Microw. Theory Tech., vol. 56, pp. 604-612, March 2008.

[7] M. Özen, R. Jos, and C. Fager, "Continuous Class-E Power Amplifier Modes," IEEE Trans. Circuit Syst. II, vol. 59, pp. 731-735, Nov. 2012.

[8] R. Marante, M.N. Ruiz, J.A. García, "A UHF Outphasing Transmitter based on Class E Power Amplifiers," INMMIC 2012, pp. 1-3, Sept. 2012. 